\title{
Research Paper: Mediating Effects of Cognitive Factors on Relation Between Behavioral Inhibition and Social Anxiety
}

Mahdi Amiri', Elham Taheri ${ }^{2 *}$, Parvaneh Mohammadkhani ${ }^{3}$, Behrooz Dolatshahi ${ }^{3}$

1. Department of Clinical Psychology, Ebn-e Sina Hospital, Mashhad University of Medical Sciences, Mashhad, Iran. 2. Department of Clinical Psychology, Tehran Psychiatric Institute, Iran University of Medical Sciences, Tehran, Iran 3. Department of Clinical Psychology, University of Social Welfare and Rehabilitation Sciences, Tehran, Iran.

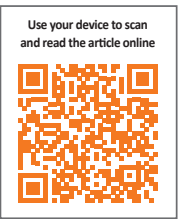

Chtation: Amiri, M., Taheri, E., Mohammadkhani, P., \& Dolatshahi, B. Mediating Effects of Cognitive Factors on Relation Between Behavioral Inhibition and Social Anxiety. Journal of Practice in Clinical Psychology, 5(3), $187-194$. https://doi.org/10.18869/acadpub.jpcp.5.3.187

https://doi.org/10.18869/acadpub.jpcp.5.3.187

Article info:

Received: 21 Jan. 2017

Accepted: 13 May 2017

Keywords:

Mediating effects, Cognitive factors, Behavioral inhibition, Social anxiety, Path analysis

\section{A BSTRACT}

Objective: The aim of this study was to investigate the interactional relationship between behavioral inhibition and cognitive factors which lead to social anxiety.

Methods: This is a cross-sectional study involving 408 participants who were recruited using convenient sampling method. All participants completed four questionnaires namely Social Phobia Inventory, Behavioral Inhibition Scales, Focus Attention Questionnaire, and Consequences of Negative Social Events Questionnaire. Data were analyzed by path analysis using LISREL software.

Results: There was a significant correlation of cognitive factors with each other $(\mathrm{P}<0.05)$ Behavioral inhibition and cognitive factors had a significant effect on upgrading social anxiety. This confirms the casual model that social anxiety is caused by behavioral inhibition along with mediation by cognitive factors.

Conclusion: This study may serve as a tool for screening and predicting the occurrence of social anxiety in students. According to the mediating effect of cognitive factors on behavioral inhibition in rising social anxiety, this knowledge can be used for prevention and treatment of social anxiety.

\section{Introduction}

ocial anxiety is defined as an evident and constant fear of social and functional conditions. The individual hypothesizes that he/ she would act shamefully and with embarrassment in certain situations, and would be judged negatively by others. People with social anxiety usually avoid participating or attending social and functional situations, and if such situations arise, they confront that with great anxiety (Rheingold, Herbert, \& Franklin, 2003). Throughout an individual's lifetime, the accession of social anxiety as a disease is estimated from 3 to 13 percent (Sadock \& Sadock, 2007). However, the burden of non-clinical and non-pathological types of social anxiety in the general population is far more. Social anxiety, both clinical and non-clinical has shown to have a negative impact on the educational, occupational

* Corresponding Author:

Elham Taheri, PhD

Address: Department of Clinical Psychology, Tehran Psychiatric Institute, Iran University of Medical Sciences, Tehran, Iran.

Tel: +98 (51) 37002317

E-mail: elhamtaheri85@gmail.com 
and relationship functions of the individual. Therefore, special considerations have been made in its etiology and treatment. Although many efforts have been made to understand the causative factors and treatment of this disorder, "there still is a long way in understanding the reason of why one gets this disorder" (Rapee \& Spence, 2004). Our knowledge of the pathology and etiology of social anxiety disorder will prove to be very useful in its prevention and treatment.

Many theoretical models have been presented to throw light on the pathology of social anxiety. Each of those models has focused on a specific aspect of the disorder. Cognitive models mainly focused on the continuation of the social anxiety disorder and seldom proceeded to the manner of its pathogenesis. The majority of these models focused on the proximal effects (present effects) like bias in judgment and memory and social stimuli explanation (Ledley, Fresco, \& Heimberg, 2006).The model of Mineka and Zinburglays main emphasis on the etiology of social anxiety disorder. Mineka and Zinburg (2006) believe that their etiology model is based on the concepts of modern learning theories, has high explanation potency and can be tested easily. Many researchers have successfully tested the theories of this model and have supported it. Furthermore, although the main emphasis is on the etiology of the disorder, modern learning theories are widely used for its prevention and treatment.

The Hoffman and Barlow and the Mineka and Zinbarg's models have both stressed on the role of evolution. The Hoffman and Barlow's model follows the triple vulnerability theory (Barlow, 2002) and tries to coordinate between different researches. This model is a compilation of the main encounters in social anxiety pathology, which have been brought together carefully. It presents a clear explanation of behavioral, cognitive and biologic factors; also, it considers the role of weak social skills in this disorder. The Rapee and Spence model is known for its integrity. This model is designed on the basis of a dimensional approach in psychopathology, and intends to clarify the spectrum of social anxiety disorder, describing it as a continuum. It has also indicated the role of different factors especially cultural elements.

The present study focuses on different theories regarding the etiology of the social anxiety disorder, with a special emphasis on the reinforcement sensitivity theory and its resulting model, i.e. the Kimbrel model. The study also focuses on the pathology of social anxiety disorder in Iranian population. We will briefly elucidate the Kimbrel (2008) model on social anxiety disorder that has the following characteristics: a) it has incorporated many factors together, b) the latest science about reinforcement sensitivity theory has been brought into it, c) it gives forth a valid explanation for differentiating the subgroups of the social anxiety disorder, d) it has spotted the role of general stressors in developing social anxiety disorder, e) it has defined a biological frame for understanding the cognitive basis of this disorder, and f) it predicts the conditions in which these cognitive biases may appear. The Kimbrel model basically explains all the risk factors according to the reinforcement sensitivity theory. Among all the models, the Kimbrel model is unique in specificity; it tries to bring forth a specific explanation for social anxiety disorder that is generalized in nature; it has also put more emphasis on the protective factors. New cognitive psychological studies have been added and the role of biological factors has been described more accurately in the Kimbrel model.

Certain temperamental traits have shown to increase the propensity of social anxiety. Moreover, some of the temperamental patterns and social anxiety disorder have the same functional mechanism. An important temperamental construct that has been studied the most in social anxiety is behavioral inhibition. Behavioral inhibition is defined as the rather constant behavioral and emotional patterns in reaction to persons, places/situations, and new stimulus. The consistency of behavioral inhibition in the first year of life is low but becomes higher and in the moderate range in the subsequent years. Also a great number of children who have had behavioral inhibition did become socially anxious (Kimbrel, 2008).

Bias and distortion in information processing and the thoughts, attitudes, beliefs related to social situations and functions, describe social anxiety. Studies have shown that these cognitive factors are seen even in children as young as 8 years old. Social anxiety starts developing when there is a vicious cycle of negative cognitive processing of social events before and after it happens. This results in anxiety and disturbs performance. Later, both avoidance and negative consequences take the opportunity of cognitive growth and reinforce the belief that social events have specific outcomes. The cognitive models support that special attention to the negative inputs and are effective in social anxiety disorder.

Different studies in this area have shown that people with social anxiety disorder pay more attention to negative or threatening information. Furthermore, they pay more attention towards themselves and less to the neutral or positive information that which disproves their negative beliefs (Hoffman \& Barlow, 2002). 
Most of the social information is vague. People with social anxiety disorder process vague information as dangerous and negative. In addition, they process others' judgments as threatening, catastrophic and intemperate. Also, they have less positive bias towards people who are not stressful. People with social anxiety disorder tend to perceive new social events as threatening, due to their previous negative experiences of psychological and physical signs of anxiety in such situations. Studies show that people with social anxiety disorder choose to remember the negative aspects of themselves in social situations and this affects their explanation of the event (Hertel, Bruzwitch, Jurman, \& Gothlip, 2008).

The present research studies the relationship between behavioral inhibition and cognitive factors in enhancing social anxiety symptoms, behavioral inhibition (in adulthood and childhood), attention bias (focusing on self and the outside), and processing bias (negative self-evaluation and the perception of other people's negative evaluation). The following study focuses on the role of temperamental and cognitive factors that act as indicators of social anxiety predictability. This study also focuses on the intercession effects of cognitive factors on connections between behavioral inhibition and social anxiety

\section{Methods}

Some of the major indices that have been introduced in the Kimbrel method as predictors of social anxiety were assessed by research tools in the nonclinical population. This is a retrospective study where the social anxiety symptoms are dependent variable or a scale wherein other variables such as behavioral inhibition (in adulthood and childhood), attention bias (on self and the outside), and explanation bias (negative self evaluation and the perception of other people's negative evaluation) are as its independent variables or predictors. The target population of this study was students studying in the universities of Iran in the year 2011-2012. Among all these students, 408 people were chosen by random sampling method. They were asked to complete the questionnaires of the study. All questionnaires were translated to Persian and then backtranslated to English. The study used various scales including Social Phobia Inventory (SPIN), Retrospective Scale of Behavioral Inhibition (RMBI), Behavioral Inhibition of Adults' Index (AMBI), Focus of Attention questionnaire, and Consequences of Negative Social Events questionnaire.

Social Phobia Inventory (SPIN): This scale was upgraded by Connor (2000) to assess social anxiety. This questionnaire is a self-report scale containing of 17 items which encompass three subscales including fear (6 items), avoidance (7 items) and physiological discomfort (4 items). Connor (2000) have reported its internal compatibility with the alpha method (0.82 to 0.94$)$. Furthermore the test retest reliability was 0.78 to 0.82 .Hassanvand Amouzadeh (2015) has reported its internal compatibility with the alpha method, 0.82 for its first half, and 0.76 for its second half. Furthermore the correlation between the two halves was 0.84 . The alpha coefficients for fear subscale, avoidance subscale and physiologic tribulation subscale are $0.74,0.75$ and 0.75 respectively.

The Retrospective Scale of Behavioral Inhibition (RMBI): This scale is an 18-item scale, which retrospectively assesses childhood (fewer than 13 years age) behavioral inhibition behaviors in adults (Goldstone \& Parker, 2005). Myers et al. (2012) reported that the internal consistency of this scale for the eighteen questions comprising AMBI total score, Cronbach's $\alpha=0.81$. The convergent validity of this scale was also found by calculating it's correlation with adult's behavioral inhibition index. This scale had a 0.55 correlation with the behavioral inhibition index of adults. Mohammadi, Fata, and Yazdandoost (2009) reported the internal consistency of this scale in a nonclinical sample containing 400 people $(\alpha=0.74)$. The reliability, tested by the test retest method, after two weeks in an 80 person sample was 0.71 . The convergent validity of this scale was also found by calculating its correlation with the adult behavioral inhibition index $(\mathrm{r}=0.55)$

The Behavioral Inhibition of Adults' Index (AMBI): This scale is a 16-item scale which has been designed to assess the mental report of the present behavioral inhibition behaviors (Goldstone \& Parker, 2005). Myers et al. (2012) reported good internal consistency of this scale for the sixteen questions comprising AMBI total score, Cronbach's $\alpha=0.84$. The convergent validity of this scale was also found by calculating its correlation with the retrospective behavioral inhibition index $(r=0.55)$. Mohammadi et al. (2009) reported that the internal consistency of this scale is 0.73 within a 400 nonclinical person sample.

The Focus of Attention Questionnaire (FAQ): This questionnaire is planned to measure the focus of attention in people to people interaction in persons with social anxiety. This questionnaire has two subscales including self-focused attention and other-focused attention, each containing 5 items (Woody, Chambless, \& Glass, 1997). The participants answer the questionnaire's items according to their previous social interactions. The Cronbach's alpha coefficient for the subscales of focus on self and focus on others were 0.76 and 0.72 respectively. The structure validity of this scale has been evaluated 
by using the study of principal components, and its two components structure has been verified. The questionnaires reliability tested by using the internal consistency coefficient according to Cronbach's alpha, for the selffocused attention and other-focused attention subscales, was 0.75 and 0.86 respectively (Khayyer, Ostovar, Latifiyan, Taghavi, \& Samani, 2008).

The Consequences of Negative Social Events Questionnaire: This questionnaire was designed to elucidate the consequences of negative social events. In this questionnaire, 16 negative social events were stated, using four subscales like negative self-assessment, negative evaluations by others, short term and long term negative consequences of social events (Wilson \& Rapee, 2005). Each of the scales proved high internal compatibility ( $\alpha=0.95$ for belief in negative evaluations by others, 0.97 for belief in negative self-evaluations, and 0.97 for belief in negative long-term consequences). In Iran, Ostovar (2007) used the two-scale form of this questionnaire reported its reliability for the negative self-appraisal $(\alpha=0.89)$, and the negative appraisal by others $(\alpha=0.90)$.

The completion of questionnaires was followed by data collection and its subsequent analysis by stepwise Multiple Regression, Path Analysis method and the SPSS16 and LISREL 8.51 software.

\section{Results}

The data collected from the questionnaires was analyzed. The sample size constituted 408 individuals; 96 percent of them were single, 4 percent married; 62 percent were females, 38 percent males. The average age was 23.41 years with a standard deviation of 3.28 . The mean and standard deviation of the scores of participants on the variables like social anxiety, behavioral inhibition in adulthood, behavioral inhibition in childhood, selffocused attention, other-focused attention, negative selfappraisal and the perception of other people's negative appraisal, have been brought together in Table 1.

The first aim of this study is to study the relation between temperamental factors (behavioral inhibition in adulthood and behavioral inhibition in childhood) and cognitive factors (self-focused attention, other-focused attention, negative self-appraisal and perception of other people's negative appraisal). The matrix of the correlation between the variables is brought forth in Table 2. As revealed, all the temperamental and cognitive variables of social anxiety have a meaningful and positive relation with one another.

The second and main aim of this study is to study the casual and etiological model of social anxiety, on basis of temperamental and cognitive factors. In order to examine the etiological model based upon the Kimbrel model which has been derived from the reinforcement sensitivity theory, the path analysis test was performed. Since the two cognitive variables of other-focused attention and the perception of other people's negative appraisal carried less weightage in predicting social anxiety symptoms, they were deleted from the model, and further analysis was done by path analysis method (Figure 1).

The path analysis method assesses whether the predicted relations between the variables match with the existing relations between the real data collected. If the two matrixes (the proposed matrix and the matrix of the real data) match, the proposed model will be considered a reliable explanation for the hypothetic relations (Meyers, Gamst, \& Guarino, 2006). The aim of this study is to as-

Table 1. Mean and standard deviation of variables

\begin{tabular}{|c|c|}
\hline Variable & Mean(SD) \\
\hline Social anxiety & $21.69(7.11)$ \\
\hline Behavioral inhibition in adulthood & $16.72(5.23)$ \\
\hline Behavioral inhibition in childhood & $29.81(5.48)$ \\
\hline Self-focused attention & $13.54(4.67)$ \\
\hline Other-focused attention & $14.87(6.89)$ \\
\hline Negative self appraisal & $23.19(10.31)$ \\
\hline Perception of other people's negative appraisal & $33.43(13.80)$ \\
\hline
\end{tabular}


Table 2. Matrix of the correlation between the variables

\begin{tabular}{|c|c|c|c|c|c|c|}
\hline Variable & $\begin{array}{l}\text { Behavioral Inhibi- } \\
\text { tion in Adulthood }\end{array}$ & $\begin{array}{l}\text { Behavioral Inhibi- } \\
\text { tion in Childhood }\end{array}$ & $\begin{array}{l}\text { Self-Focused } \\
\text { Attention }\end{array}$ & $\begin{array}{l}\text { Other- } \\
\text { Focused } \\
\text { Attention }\end{array}$ & $\begin{array}{l}\text { Negative Self } \\
\text { Appraisal }\end{array}$ & $\begin{array}{l}\text { Perception of } \\
\text { Others Negative } \\
\text { Appraisal }\end{array}$ \\
\hline $\begin{array}{l}\text { Behavioral inhibi- } \\
\text { tion in adulthood }\end{array}$ & 1 & & & & & \\
\hline $\begin{array}{l}\text { Behavioral inhibi- } \\
\text { tion in childhood }\end{array}$ & 0.67 & 1 & & & & \\
\hline $\begin{array}{c}\text { Self-focused atten- } \\
\text { tion }\end{array}$ & 0.37 & 0.34 & 1 & & & \\
\hline $\begin{array}{l}\text { Other-focused at- } \\
\text { tention }\end{array}$ & 0.36 & 0.26 & 0.57 & 1 & & \\
\hline $\begin{array}{l}\text { Negative self ap- } \\
\text { praisal }\end{array}$ & 0.39 & 0.35 & 0.55 & 0.49 & 1 & \\
\hline $\begin{array}{l}\text { Perception of other } \\
\text { negative appraisal }\end{array}$ & 0.32 & 0.29 & 0.39 & 0.62 & 0.38 & 1 \\
\hline
\end{tabular}

sess the variables that constitute the Kimbrel model. This model claims that behavioral inhibition, as a primary and remote factor, accompanied by cognitive factors, causes social anxiety symptoms. The hypothetic casual model was assessed with the LISREL software version 8.51. This model was analyzed with six fit measures.

The results of the analysis done by means of the six fitness indices confirm the hypothetic casual structure. The chi-square and the Root Mean Square Wrong of Approximation (RMSEA) are absolute appropriate measures. The chi-square statistics were performed in order to examine the difference between the predicted relations and the ob- served relations (correlations and covariance). Because the researcher predicts the fitness or similarity (and not the difference), the meaningless chi-square is ideal. The more the sample size, the more potent the chi-square test gets. Therefore, in sample sizes over 200, the chi-square is meaningful and although the difference is little, the models acceptance is weak. According to these considerations, the model which has the smallest chi-square is preferred (Meyers et al., 2006). In this study the chi-square in the casual structure, was 421.14(df=407, $\mathrm{N}=408), \mathrm{x}^{2}<0.001$. The other index which is introduced to obviate the limitation of the chi-square statistics is the $\mathrm{x}^{2} / \mathrm{df}$ which if lesser than 3, indicates the fitness of the model (Meyers et al.,

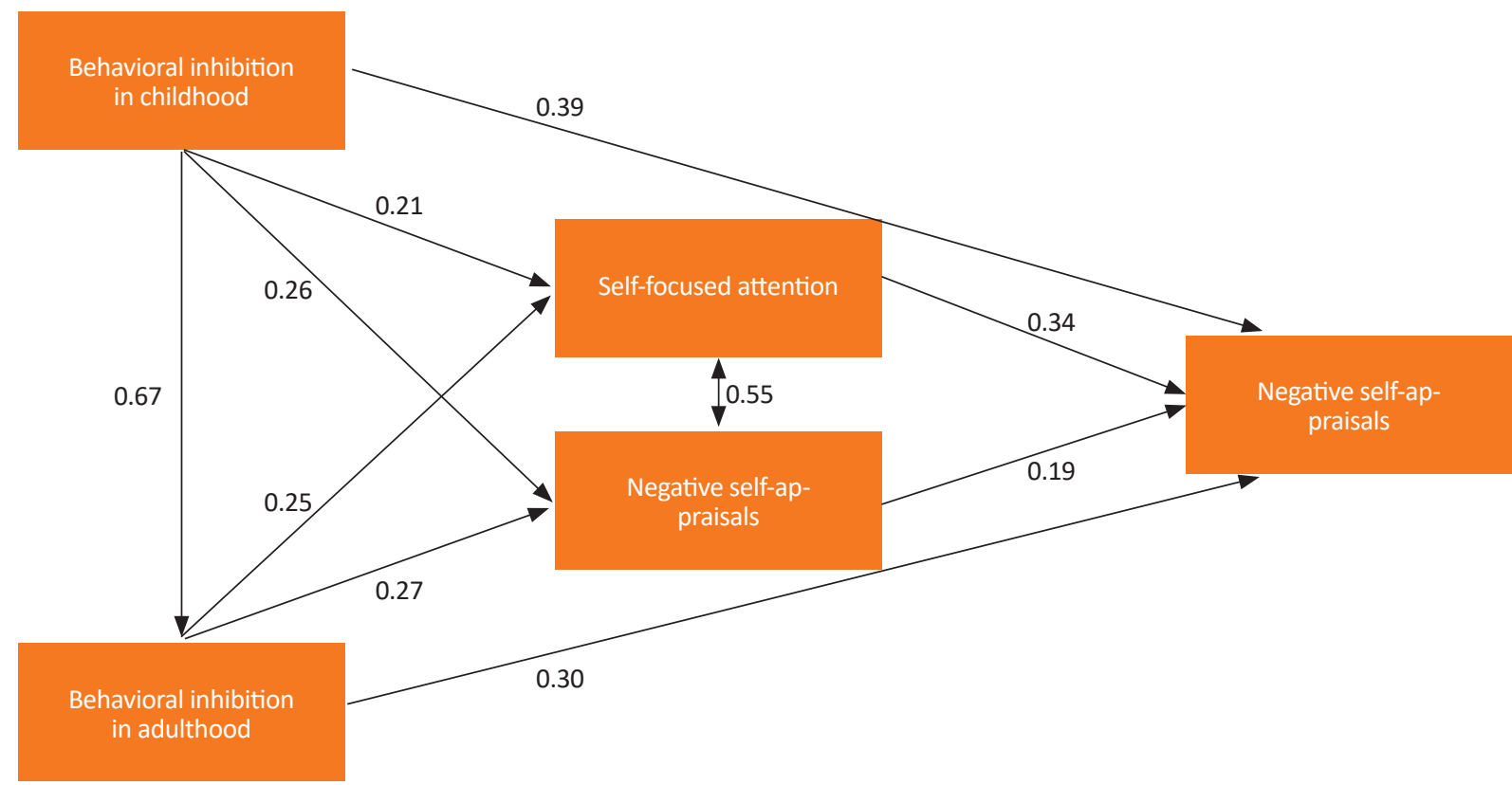

Figure 1. Structural relations of etiological model of social anxiety 
2006). In this study the $\mathrm{x}^{2} / \mathrm{df}$ is 1.03 which shows the fitness of the casual structure under study.

Lohelin (2004) recommended this index as an indicator of the root mean square wrong of approximation (RMSEA) fitness: lesser than 0.08 shows fitness, 0.08 to 0.1 : medium fitness and greater than 0.1 shows weak fitness. In this study, the RMSEA was 0.051 which indicates good fitness of the data with the casual structure. CFI, NFI, RFI, IFI are the comparative indices of fitness. These indices compare the hypothetic model with the null model. In this study these indices were 0.94, 0.85, 0.82 , and 0.90 , respectively. These numbers represent moderate to good fitness of the hypothetic casual model (Meyers et al., 2006).

In general, the results of the path analysis show that the casual model presented has good fitness with the research data. Therefore, by generalizing the results of this study in the general population, it can be said that the temperamental behavioral inhibition factor causes social anxiety disorder, via the cognitive factors of self-focused attention and negative self-appraisal.

\section{Discussion}

The first goal of this study was to investigate the relation between temperamental factors (the adulthood behavioral inhibition and childhood behavioral inhibition variables) and cognitive factors (self-focused attention, other-focused attention, negative self-appraisal and perception of other's negative appraisal). As reported, the relation between all these variables was meaningful in stages lower than 0.05 . This shows the fact that the natural behavioral inhibition factor is related to the cognitive beliefs of people with social anxiety symptoms. This result is in concordance with the previous hypothesis and conclusions (Kimbrel, 2008).

In this study there was a meaningful relation between behavioral inhibition in childhood and adulthood, and social anxiety and it also corresponds with the reports handed by Hirshfeld-Becker, Biderman and Rosenboum (2000). They realized the relation between behavioral inhibition and social anxiety. The natural structure of behavioral inhibition has always been considered as a fundamental and basic factor in causing clinical anxiety. Behavioral inhibition is an important risk factor in causing social anxiety (Kimbrel, 2008). In this study the two variables of negative self-appraisal and cognition of other people's negative appraisal, have positive and meaningful relation with social anxiety. This result matches with the results of studies conducted by Stopa and Clark (2000).
Stopa and Clark (2000) believed that people with social anxiety have more negative self-appraisal ideas as compared with normal people. Furthermore, they found a positive and meaningful relation between negative self-appraisal and cognition of other people's negative appraisal with social anxiety. In addition, there was a meaningful relation between self-focused inquest and other-focused inquest with social anxiety symptoms. But, as a casual discussion, we can only admit the relation, because the type of relation is a correlation type. Therefore, we cannot tell the way of relation and which factors have more effect on this relation. In order to clarify the way of relation and the manner of effect of the natural factors (behavioral inhibition) and cognitive factors, further studies and analysis are needed.

According to the relation between natural and cognitive factors, we can successfully deduce that the natural factor of behavioral inhibition, accompanied with the cognitive factors of self-focused attention and negative self-appraisal, create the social anxiety disorder. Investing the validity of this casual presumption and determining the extent and nature of this relation is the second and main aim of this study. The results of the path analysis of the statistics showed that the data or observations of this study are correspondent with the casual pattern resulted from the Kimbrel model (2008) about the development of social anxiety disorder. Therefore, we can conclude that behavioral inhibition as a natural factor in combination with cognitive factors leads to social anxiety symptoms.

In this way that behavioral inhibition (a natural-biologic factor) in mediation with cognitive factors (the factor more resulted from learning) creates the physical, behavioral and cognitive symptoms of social anxiety. The behavioral inhibition system is the main agent responsible for resolving the conflicts between aims that challenge with each other (like the closeness-avoidance conflict) and does this by halting powerful and prominent behaviors, increasing attention, increasing the excite arousal and activating the danger assessment behaviors (McNaughton \& Corr, 2004).

The danger assessment behaviors include searching the environment and the memories relevant to danger and threat (Corr, 2004). Although because of the evolutionary pressures, the behavioral inhibition system has bias on information about the potentially threatening situations and avoiding reactions are always preferred. Also, the behavioral inhibition system is defined as the neuronal basis of anxiety, and an increase in the activity of the behavioral inhibition system is responsible for many disorders such as general anxiety and neurotic depres- 
sion (Gray \& McNaughton, 2000). Therefore, those who have a higher sensitivity of the behavioral inhibition system must have the most intensive anxiety and avoidance in reaction to social threatening stimulants.

The second and main goal of this research was to research the casual and etiologic pattern for social anxiety on the basis of the cognitive and natural factors. In general, the results of the path analysis show that the etiologic model presented, is well coordinated with the research data. Hence, by generalizing the results of this study to the population, it can be understood that the natural factor of behavioral inhibition, with mediation of the cognitive factors of self-focused attention and negative self-appraisal, cause the social anxiety symptoms.

The model introduced for the development and persistence of social anxiety disorder is based on the reinforcement sensitivity theory. This model places several hypotheses. Firstly, according to the equifinality rule, the introduced model assumes there are several causative factors, including genetic and environmental factors for social anxiety disorder. Secondly, according to the multifinality rule, common start points can have different results and therefore, not all of the children with behavioral inhibition get social anxiety disorder, and not all the persons with social anxiety disorder had high behavioral inhibition in their childhood. Also according to the linear pattern of the relations in the Kimbrel model, cognitive factors (in this study, self-focused attention and negative self-appraisal) are the medium for the effect of the natural factor of behavioral inhibition in causing social anxiety disorder symptoms.

Since not all the children with high behavioral inhibition get social anxiety disorder, and not all people with social anxiety disorder had a history of high behavioral inhibition in their childhood (Kimbrel, 2008), this result seems to be natural and logical in coordination with the casual model of Kimbrel. Cognitive bias (such as negative beliefs and expectations, negative attention and memory bias on threatening social information) has an important role in the continuum of the social anxiety symptoms (Clark \& Wells,1995).

Amir, Foa and Coles (1998) found that people with general social anxiety have more tendencies in explaining vague social stories negatively. There is also some evidence showing that people with general social anxiety have more tend in focusing on threatening social information. Spector, Pecknold and Libman (2003) found that people with social anxiety disorder have more bias in reacting to negative appraisals (such as sneer or criticism) and notice- able aspects of anxiety (like being ashamed and flushing). In addition, those people with social anxiety tend to focus more on themselves in social situations, which results in raising their anxiety (Bogels \& Mansell, 2004).

It can be said that the natural and basic factor such as behavioral inhibition, and cognitive factors that result from learning, can play individual and mutual role in the etiology of many psychological disorders especially social anxiety disorder. Therefore, with this knowledge and a better understanding of psychopathology of social anxiety symptoms, we can successfully aim towards prevention and treatment of social anxiety disorder in people.

\section{Acknowledgements}

This research did not receive any specific grant from funding agencies in the public, commercial, or not-forprofit sectors.

\section{Conflict of Interest}

The authors declared no conflicts of interest.

\section{References}

Amin, N., Foa, E. B., \& Coles, M. E. (1998). Negative interpretation bias in social phobia. Behaviour Research and Therapy, 36(10), 945-957. doi: 10.1016/s0005-7967(98)00060-6

Barlow, D. H. (2002). Anxiety and its disorders. New York: Guilford Press.

Bögels, S. M., \& Mansell, W. (2004). Attention processes in the maintenance and treatment of social phobia: Hypervigilance, avoidance and self-focused attention. Clinical Psychology Review, 24(7), 827-56. doi: 10.1016/j.cpr.2004.06.005

Clark, D. M., \& Wells, A. (1995). A cognitive model of social phobia. In M. R. Liebowitz (Ed.), Social Phobia: Diagnosis, Assessment, and Treatment (pp. 69-93). New York: Guilford Press.

Connor, K. M. (2000). Psychometric properties of the Social Phobia Inventory (SPIN): New self-rating scale. The British Journal of Psychiatry, 176(4), 379-386. doi: 10.1192/bjp.176.4.379

Corr, P. J. (2008). The reinforcement sensitivity theory of personality. Cambridge: Cambridge University Press.

Corr, P. J. (2004). Reinforcement sensitivity theory and personality. Neuroscience and Biobehavioral Reviews, 28(3), 317-32. doi 10.1016/j.neubiorev.2004.01.005

Gladstone, G., \& Parker, G. (2005). Measuring a behaviorally inhibited temperament style: Development and initial validation of new self-report measures. Psychiatry Research, 135(2), 133-43. doi: 10.1016/j.psychres.2005.03.005 
Gray, J. A., \& McNaughton, N. (2000). The neuropsychology of anxiety: An enquiry into the functions of the septo-hippocampal system. $\left(2^{\text {nd }} \mathrm{Ed}.\right)$. New York: Oxford University Press.

Hassanvand Amouzadeh M. (2015). [The standardization of Social Phobia Inventory (SPIN) in nonclinical Iranian samples (Persian)]. Urmia Medical Journal. 26(1), 17-30.

Hertel, P. T., Brozovich, F., Joormann, J., \& Gotlib, I. H. (2008). Biases in interpretation and memory in generalized social phobia. Journal of Abnormal Psychology, 117(2), 278-88. doi: 10.1037/0021-843x.117.2.278

Hirshfield-Becker, D. R., Biederman, J., \& Rosenbaum, J. F. (2004). Behavioral inhibition. In T. L. Morris \& J. S. March (Eds.), Anxiety Disorders in Children and Adolescents (pp. 27-58). New York: Guilford.

Hofmann, S. G., \& Barlow, D. H. (2002). Social phobia (social anxiety disorder). In D. H. Barlow (Ed.), Anxiety and Its Disorder (pp. 454-76). (2 ${ }^{\text {nd }}$ Ed.). New York: Guilford Press.

Khayyer, M., Ostovar, S., Latifian, M., Taghavi, M. R., \& Samani, S. (2008). [The study of mediating effects of self-focused attention and social self-efficacy on links between social anxiety and judgment biases (Persian)]. Iranian Journal of Psychiatry and Clinical Psychology. 14(1), 24-32.

Kimbrel, N. A. (2008). A model of the development and maintenance of generalized social phobia. Clinical Psychology Review, 28(4), 592-612. doi: 10.1016/j.cpr.2007.08.003

Ledley, D. R., Fresco, D. M., \& Heimberg, R. G. (2006). Cognitive vulnerability to social anxiety disorder. In L. B. Alloy \& J. H. Riskind (Eds.), Cognitive Vulnerability to Emotional Disorders (pp. 251-84). Mahwah, NJ: Lawrence Erlbaum Associates.

Loehlin, J. C. (2004). Latent variable models: An introduction to factor, path, and structural analysis. (4 $4^{\text {th }} \mathrm{Ed}$.). Mahwah, NJ: Erlbaum.

McNaughton, N., \& Corr, P. J. (2004). A two-dimensional neuropsychology of defense: Fear/anxiety and defensive distance. Neuroscience \& Biobehavioral Reviews, 28(3), 285-305. doi: 10.1016/j.neubiorev.2004.03.005

Meyers, L. S., Gamst, G., \& Guarino, A. J. (2006). Applied multivariate research: Design and interpretation. Philadelphia: Sage.

Mineka, S., \& Zinbarg, R. (2006). A contemporary learning theory perspective on the etiology of anxiety disorders: It's not what you thought it was. American Psychologist, 61(1), 10-26. doi: 10.1037/0003-066x.61.1.10

Mohammadi, A., Fata, L., \& Yazdandoost, R. (2009). [Predictors of obsessive-compulsive symptoms in students (Persian)]. Iranian Journal of Psychiatry and Clinical Psychology, 15(3), 274-282.

Myers, C. E., VanMeenen, K. M., Devin McAuley, J., Beck, K. D., Pang, K. C. H., \& Servatius, R. J. (2011). Behaviorally inhibited temperament is associated with severity of post-traumatic stress disorder symptoms and faster eyeblink conditioning in veterans. Stress, 15(1), 31-44. doi: $10.3109 / 10253890.2011 .578184$

Ostovar, S. (2007). [Explanation of mediating effect of self focused attention and social self efficacy on relationship between social phobia and cognitive biases (Persian)] (PhD dissertation) Shiraz: Shiraz University.
Rapee, R. M., \& Spence, S. H. (2004). The etiology of social phobia: empirical evidence and an initial model. Clinical Psychology Review, 24(7), 737-67. doi: 10.1016/j.cpr.2004.06.004

Rheingold, A. A., Herbert, J. D., \& Franklin, M. E. (2003). Cognitive bias in adolescents with social anxiety disorder. Cognitive Therapy and Research, 27(6), 639-55. doi: 10.1023/a:1026399627766

Sadock, B. J., \& Sadock, V. A.(2007). Synopsis of psychiatry. ( $9^{\text {th }}$ Ed.) Philadelphia: Lippincott Williams \& Wilkins.

Spector, I. P., Pecknold, J. C., \& Libman, E. (2003). Selective attentional bias related to the noticeability aspect of anxiety symptoms in generalized social phobia. Journal of Anxiety Disorders, 17(5), 517-31. doi: 10.1016/s0887-6185(02)00232-3

Stopa, L., \& Clark, D. M. (2000). Social phobia and interpretation of social events. Behaviour Research and Therapy, 38(3), 273-83. doi: 10.1016/s0005-7967(99)00043-1

Wilson, J. K., \& Rapee, R. M. (2005). The interpretation of negative social events in social phobia: Changes during treatment and relationship to outcome. Behavior Research and Therapy, 43(3), 373-89. doi: 10.1016/j.brat.2004.02.006

Woody, S. R., Chambless, D. L., \& Glass, C. R. (1997). Self-focused attention in the treatment of social phobia. Behaviour Research and Therapy, 35(2), 117-29. doi: 10.1016/s0005-7967(96)00084-8 